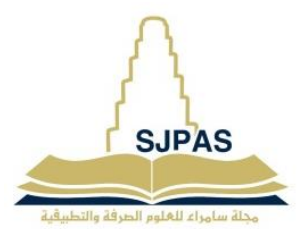

\title{
التأثير التثبطي للنوعين القيصوم Achillea conferta والقنفذي Echinops chardinii من العائلة النجمية Asteraceae في بعض التئية الانواع المايكروبية
}

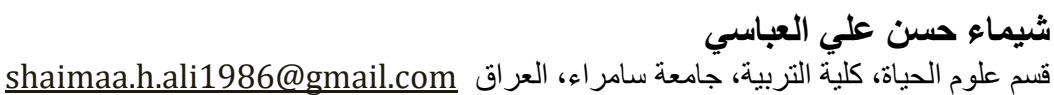

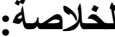

تضمنت الدراسة الحالية معرفة الخصائص الكيميائية الحيوية والتاثير المثبط الميكروبي لنو عين (Echinops charadinii و Achillea conferta). من الن النية

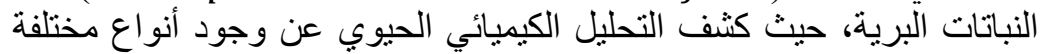

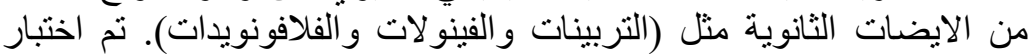

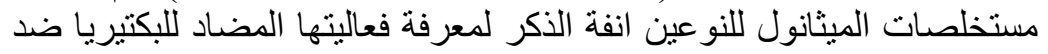
خمسة انواع مايكروبية ممرضة Bacillus ،Staphylococcus aureus ، Pseudomonas aeruginosa، Escherichia coli 'pumilus الأCandida Albicans

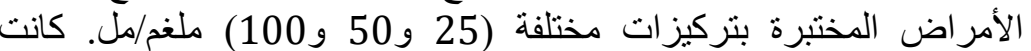
المكورات العنقودية الذهبية Staphylococcus aureus أكثر الممرضينات

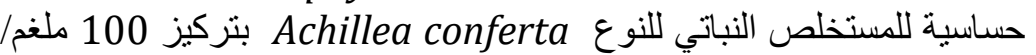

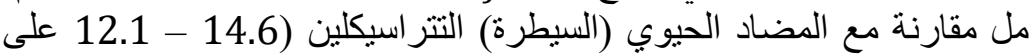

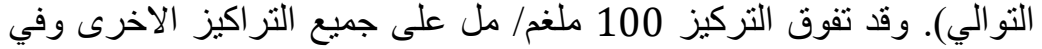

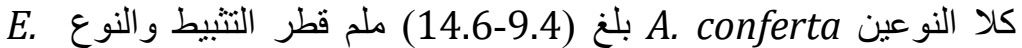
chardinii الفطري C.albicans الذي لم يسجل اي تأثثير يذكر نستنتج من هذا النه قد يكون المستخلص الميثانولي للنو ع Achillea conferta قدرة على لمئ معالجة مسببات

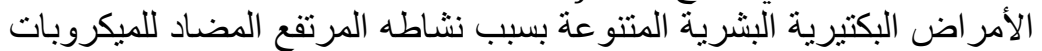

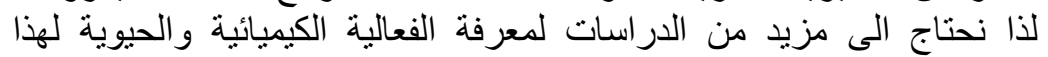

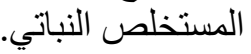

\begin{tabular}{|c|}
\hline معلومات البحث: \\
\hline تأريخخ القبـــــام: 2020/07/10 \\
\hline الكلمات المفتاحية: \\
\hline
\end{tabular}

Achillea conferta, Echinops chardini, Asteraceae, Staphylococcus aureus, Terpenes, Phenols, Flavonoids, Pseudomonas aeruginosa, Candida albicans

استخدمت النباتات الطبية في الماضي القريب كادوية لعلاج عديد من الإمر اض، وفي در اسة Kunwar وجماعته [1] تمت الإع

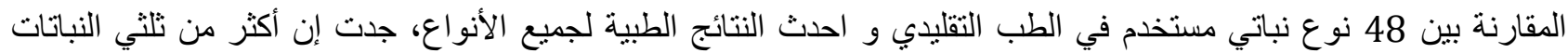

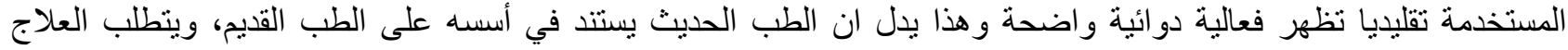

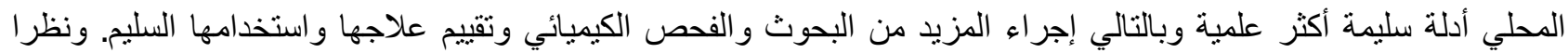
لتسبب العلاجات الكيميائية المصنعة بكثير من المخاطر ، لذلك كانت هنالك طرقاً بديلةً استحدثت خلال السنوات القات القليلة الماضية

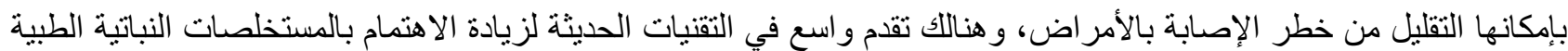
إذ تمنلك نباتات عدة خصائص دوائية ذات إمكانية عالية في التطبيقات العلاجية، وفي العائلة النجمية Asteraceae (العائلة

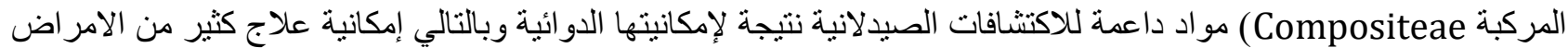


تثنير الدر اسات الحالية إلى أن نسبةَ كبيرةً من السكان في دول عدة تعتمد على الممارسات التقليدية والنباتات الطبية الثنائعة

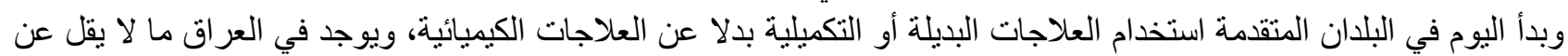

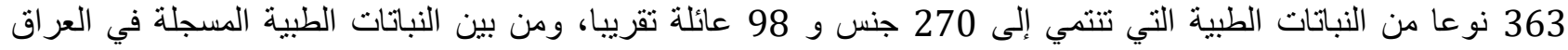
و المدروسة فعاليتها الطبية التي تعود إلى العائلة النجمية هي الأنواع ، Matricaria Chamomilla Carthemus tinctoris،

.[3] · Artemisia canpestris ‘Anthemis nobilis

تنتج النباتات مركبات كيميائية عدة التي تعد نواتج أيض ثانوية ومنها الفلافونويدات اذ تشكل مجموعة كبيرة من النواتج

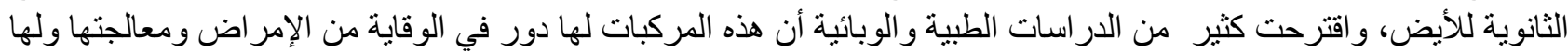

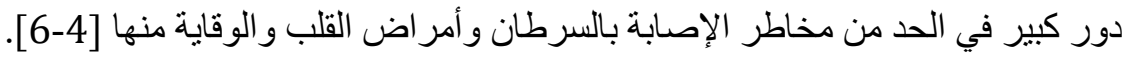

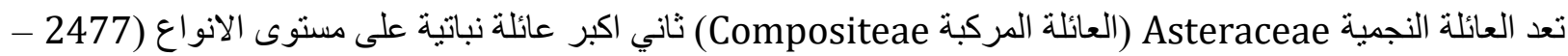
26000 نوع ) و اكبر عائلة نباتية على مستوى الاجناس (1568-1623 جنس) [8،8]، و واسعة الانتشار في العالم (عدا القارتين tropical من المناطق الاستو ائية وشبه الاستو ائية

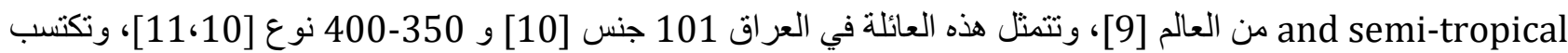
هذه العائلة اهميتها في المجالات: البيئية والغذائية والصناعية والطبية والصيدلانية [2،12-15]، وذللك لمحتو اها من الايضات

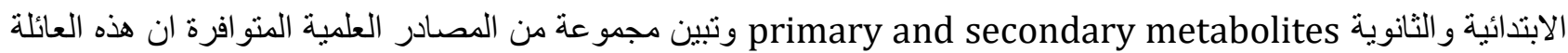
تحظ باهتمام عالمي و اسع الا انها لم تأخذ الاهتمام نفسه في العراق اذ هناللك ندرة في الدر اسات المحلية على افر اد هذه العائلة التئي بدورها اقتصرت على الجانب الوصفي و التشريحي للنبات [16]، وتكاد التهاد تخلو من جانب المحتوى الكيميائي الفعال و الفعالية

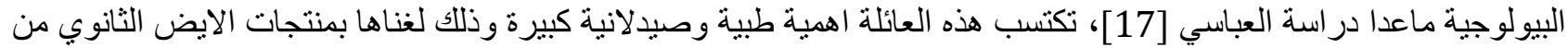

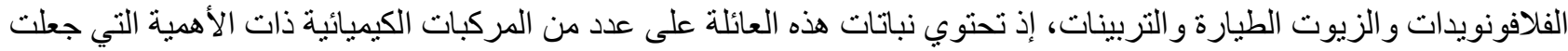

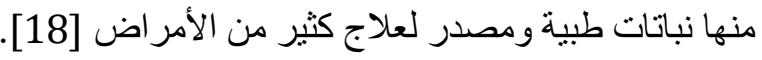

ان المركبات المميزة للعائلة النجمية هي الكلايكوسيدات و الفينولات و الفلافونويدات [19]، و والتربينات [20]، و والسكريات

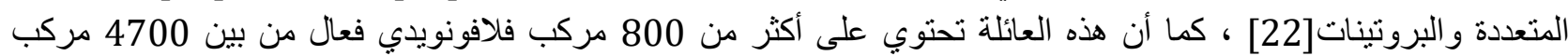

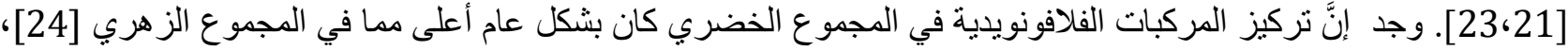

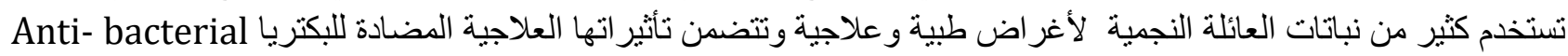
و الفطريات Anti-fungal و الديدان Anti-helminthic ومكافحة الحشرات الضارة وبعض الابتدائيات الممرضة كما تستخدم

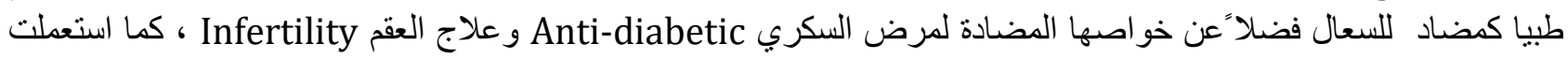

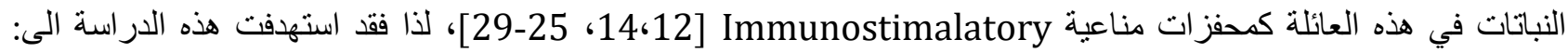

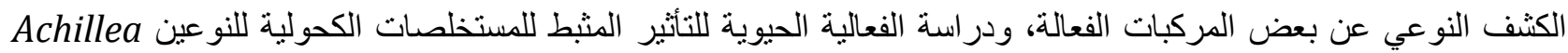
Echinops chardinii و لبعض الانواع البكتيرية و الفطرية.

جمعت عينات افراد العائلة النجمية Asteraceae للنوعين Achillea conferta من العشيرة Anthemidia و من من من شمال العراق مقاطعة السليمانية Cichorea Sulainops chardinii

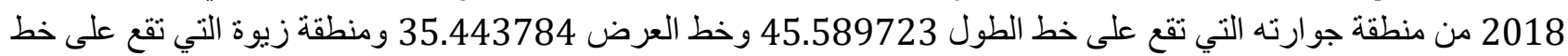
الطول 44.9023951 و خط العرض 37.2461556، من جبال ووديان عائدة للمقاطعة المدروسة. تم تشخيص النباتات استنادا

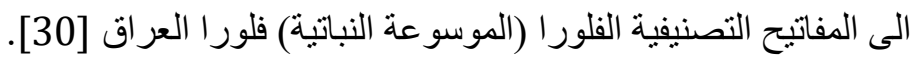

الكثوفات النوعية الاولية

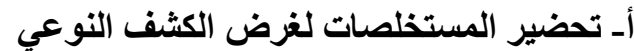
أخذ 1غم من المادة الخام المطحونة من النبات (كامل النبات فوق التربة Total و الاز هار فقط Flower) قيد الدر اسة ونقعت في

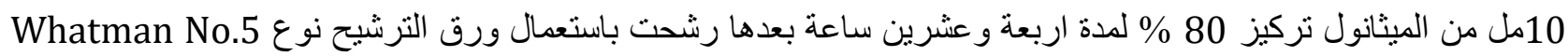


بـ اختبارات الكشف عن المواد الفعالة كثف القلويدات ـ كاثف ماير Mayer Reagent تم اضافة قطرات من كاثف ماتف ماير الىى 1 مل من المستخلص تكون لون ابيض او راسب ابيض الى وردي دلالة على وجود القلويدات [43]. كاثف التربينات Terpenes Reagent: تم اضافة 1 مل مستخلص و 1 مل من كاشف ترم هيل ثم وضع في حمام مائي وان تكون لون ازرق او اخضر دل على وجود التربينات [44].

كاشف الكلايكوسيدات Glycosides Reagents: مزجت كمية متساوية من المستخلص مع قطرات من الكاشف اذ ان تكون لون اصفر دلالة على وجود الكلايكوسيدات [45 الثيل

كاشف الصابونيات Saponins Reagents مزج 1 مل من المستخلص مع 1 مل من (1\% كلوريد الزئبق وان تكون راسب ابيض يدل على وجود الصابونيات [31] .

كواشف الفينولات Shenols Reagents

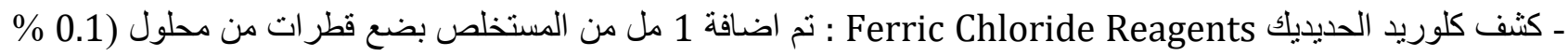

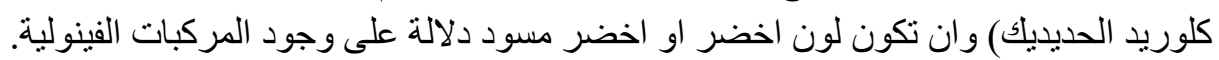

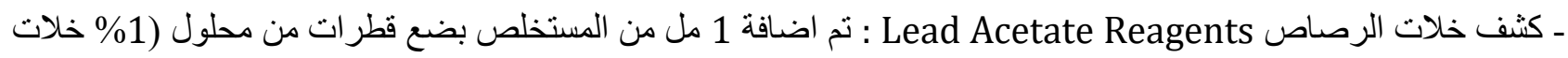
الرصاص القاعدي المائي). تكون لون كريمي جيلاتيني مع راسب على وجود التباين والفينو لات .

كاشف التانينات Tannins Reagents :كاشف كلوريد الحديديك Ferric Chloride Reagent: تم إضافة امل من المستخلص بضع قطر ات من محلول (0.1 \% كلوريد الحديديك) وأن تكون لون أخضر أو أخضر مسود دلالة على وجود مركبات

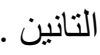

كواشف الفلافونيدات Flavonoids Reagents ـ كثف Zinc-HCI Reduction: يثير ظهور اللون القرمزي عند إضافة 25 ملغم من مسحوق الزنلك والقليل من قطرات

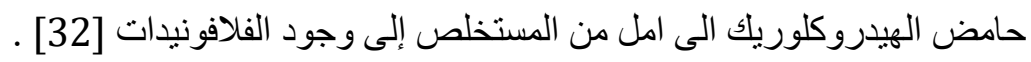

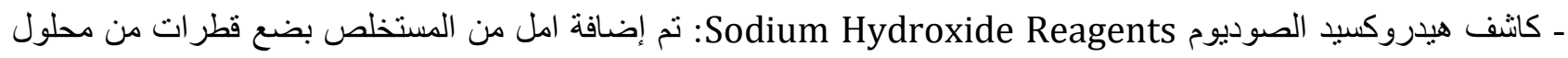
هيدروكسيد الصوديوم وان تكون لون اصفر يختفي عند إضافة قطر ات من حامض مخفف دل على وجود الفلافونيدات [33].

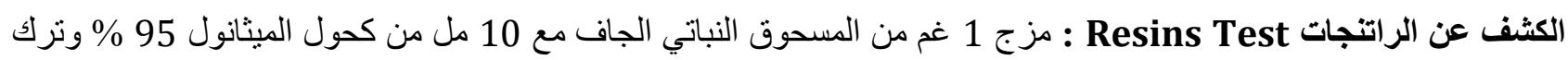

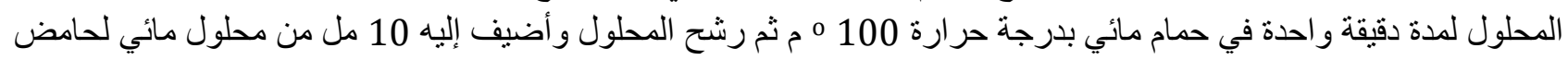

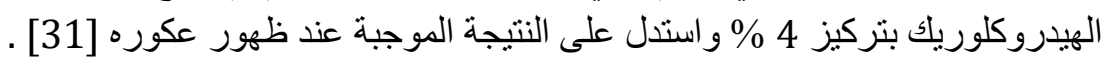

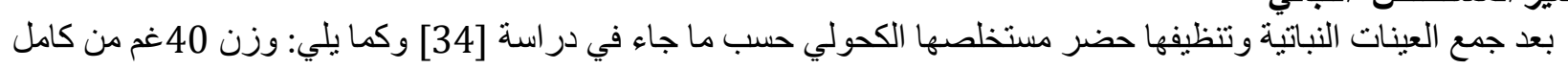

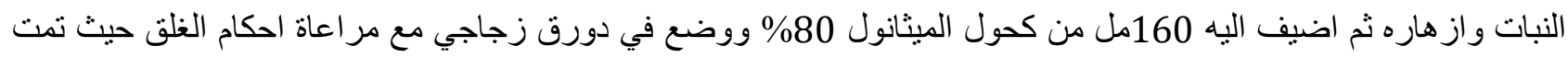

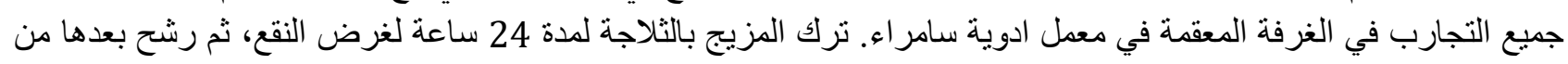

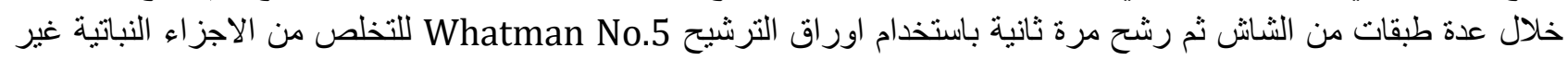

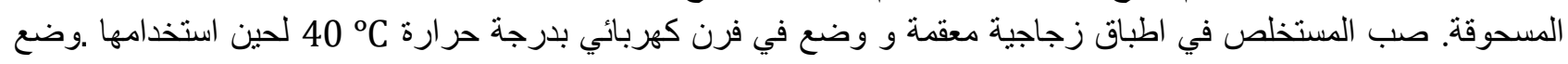

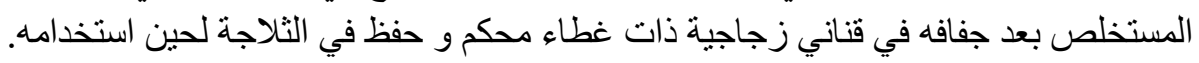

تعقيم المستخلصات وتحضير التراكيز المستخدمة في الدراسة .

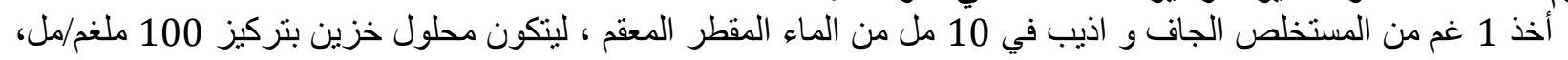
عقم المحلول باستخدام مرشحات ميكروبية معقمة الموجودة فيه و الحصول على محلول خزين معقم [35] و حضرت منه تر اكيز (25، 50 ، 100 \%). 


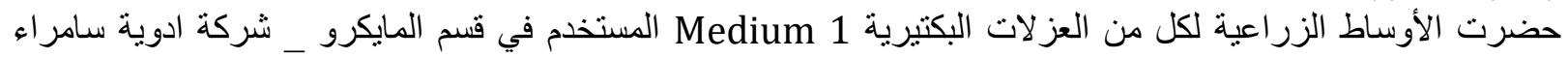

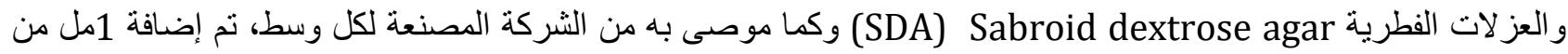

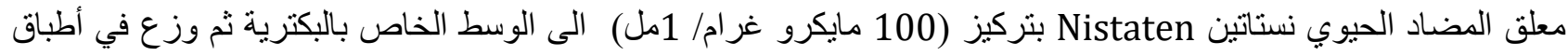

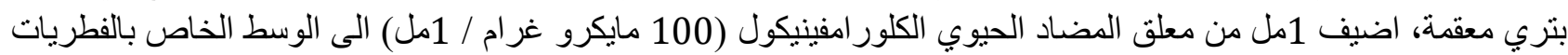

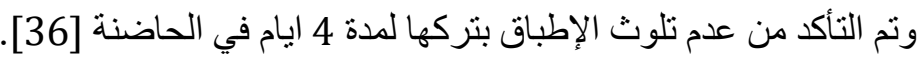

تعضد التحضير المعلق البكتيري Bacterial inoculation تم تحضير المعلق البكتيري من مستعمرة بعمر 24 ساعة و الذي ينت بأخذ مسحة من البكتريا المعزولة بواسطة عروة التلقيح

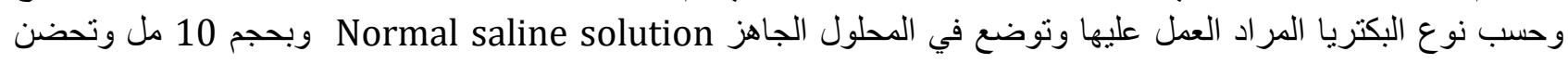
لمدة 24 ساعة [37] لضمان الحصول الصراد العلى على ودو كافي من خلايا البكتريا المدروسة.

Fungal inoculation تحضير المطلق الفطري تم تحضير اللقاح بنقل جزء من المستعمرة الفطرية النامية على وسط السابرويد بعد تنشيطها حيث تم النقل باستخدام إبرة

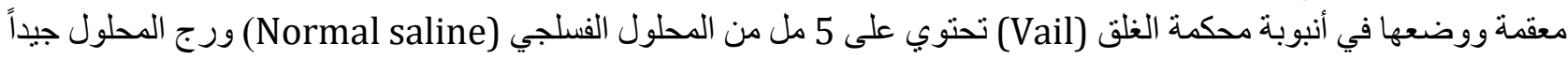
لضمان تجانس وتوزيع الاسبور ات الفية الفرية.

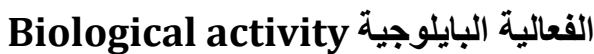 تحضير الأطباق الخاصة بالبكتريا لاختبار الفعالية الحيوية للمستخلصات .}

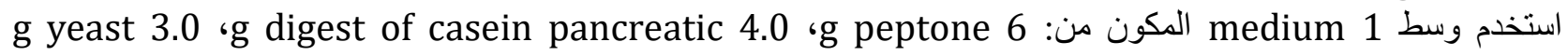
Cylinder - plate method وبحسب طريقه water .ml 1000 ،g agar 15.0 ،g beef extract 1.5 ،extract

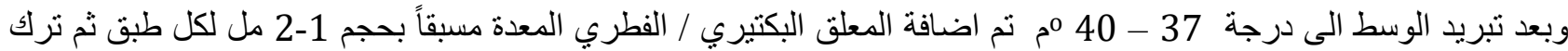

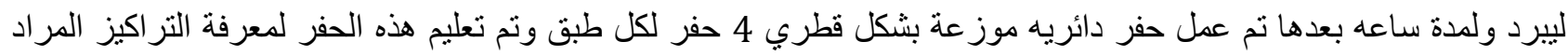

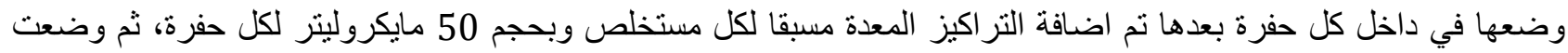

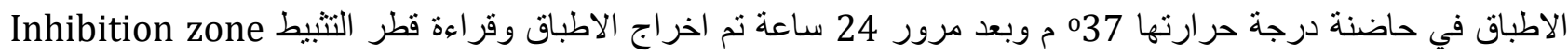

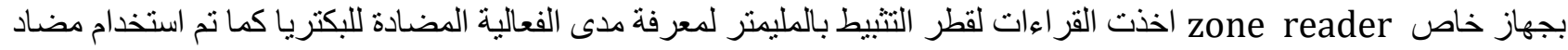

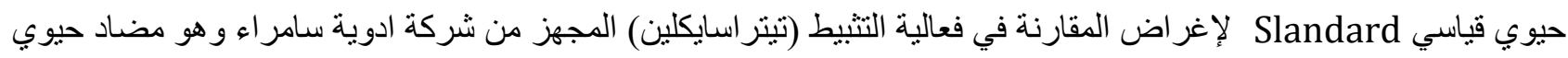
فعال ضد كل من البكتريا الموجبة والسالبة لصبغة كرام ..

تحضير الاطباق الخاصة بالفطر Candida albicans لاختيار الفعالية الحيوية للمستخلصات .

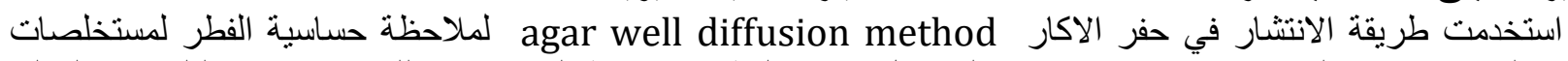

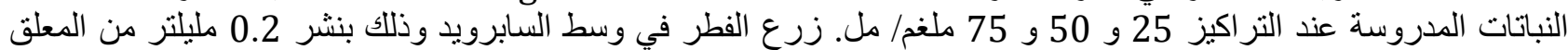

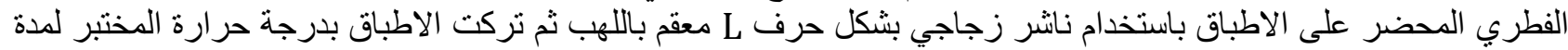

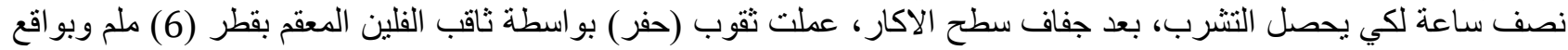

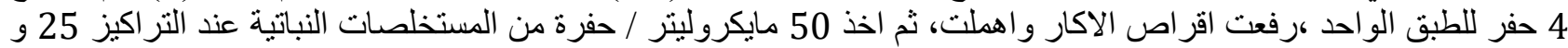

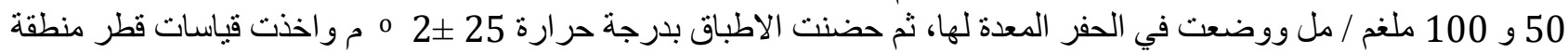

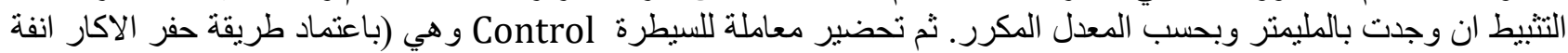
الذكر تم وضع 50 مايكروليتر /حفرة من المضاد الحيوي ( التيتر اسايكلين بالحفرة المخصصة (السيطرة) . 
التحري الكيميائي عن المواد الفعالة في النوعين Achillea conferta و Echinops chardinii

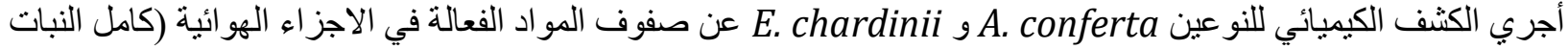

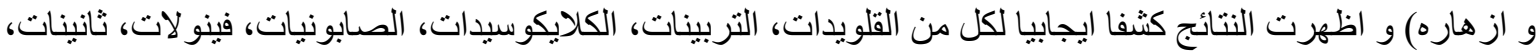

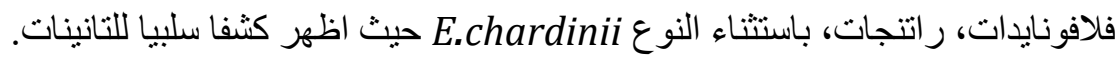

وقد اعطى النوع Achillea conferta كثفا ايجابيا لمغظم الكواشف المدروسة الا انه تفوق في اظهار الفينولات

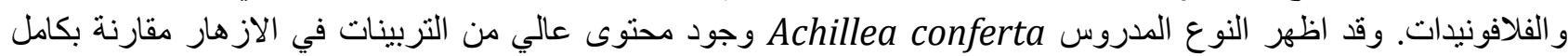
النبات فوق التربة. اما النوع Echinops chardinii فقد اعطى هو الاخر كثفا ايجابيا لمعظم صفوف المواد النئ الفعالة المدروسة

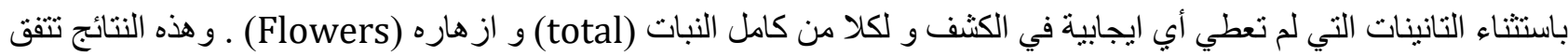

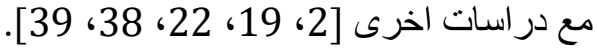

جدول 1: الكثف الكيميائي للنو عين Achillea conferta و Echinops chardinii لكامل النبات و ازهاره.

\begin{tabular}{|c|c|c|c|c|c|c|c|c|c|c|c|}
\hline \multirow[t]{2}{*}{$\mathbf{T} / \mathbf{F}$} & \multirow[t]{2}{*}{ راتنجات } & \multicolumn{2}{|c|}{ فلافونويدات } & & \multicolumn{2}{|c|}{ فينولات } & \multirow{2}{*}{ 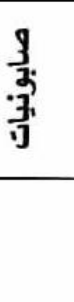 } & \multirow{2}{*}{ كلايكوسيدات } & \multirow{2}{*}{ تربينات } & \multirow{2}{*}{ قَلويدات } & \multirow{2}{*}{ النوع } \\
\hline & & هينروكسيدا & زنتك & & خلات & الحلويديك & & & & & \\
\hline \multicolumn{12}{|c|}{ Tribe :Anthemidia } \\
\hline $\mathbf{T}$ & + & + & ++ & + & + & + & + & + & + & + & A.conferta \\
\hline $\mathbf{F}$ & + & + & $+H$ & + & + & ++ & + & + & ++ & + & A. conferta \\
\hline \multicolumn{12}{|c|}{ Tribe :Cichoria } \\
\hline$T$ & + & + & + & - & - & + & + & + & + & + & E. chardinii \\
\hline $\mathbf{F}$ & + & + & + & - & - & + & + & + & + & + & E. chardinii \\
\hline
\end{tabular}

كامل النبات فوق التربة = الإز

F. flower = الاز هار فقان فئ

تأثير المستخلصات الكحولية للنوعين Achillea conferta في الانواع الميكروبية المدروسة اوضحت الدراسة تأثير المستخلصات الكحولية للنوعين Achillea conferta و

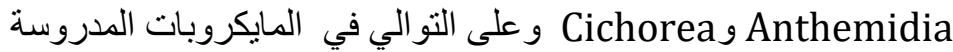
جدول 2 لوحة 1 و2

يُلاحظ من الجدول 2، ان المستخلص الكحولي للنوع النباتي A.conferta وبالتر اكيز كافة قد اثرت في جميع المايكروبات،

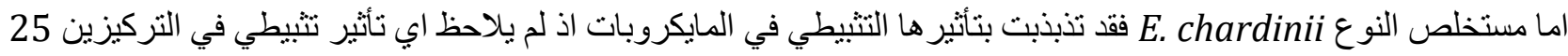

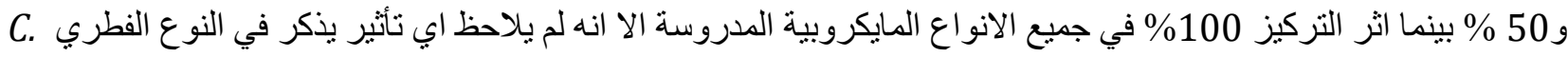

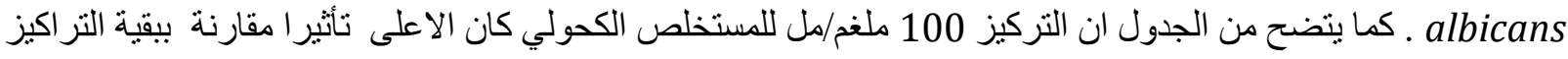
الأخرى. 
وتبين من الجدول ان المستخلص الكحولي بتركيز 25 ملغم/مل للنوع A. conferta قد حقق تنبيطاً واضحاً للمايكروبات

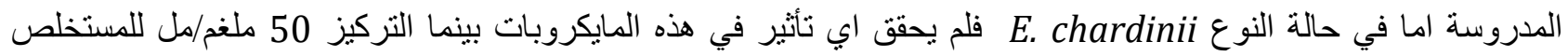

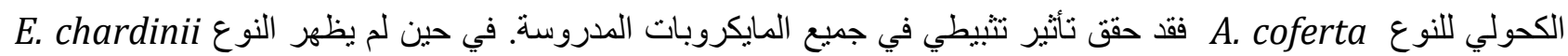

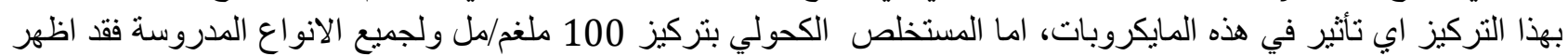

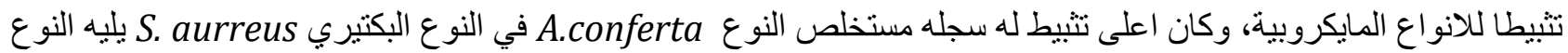

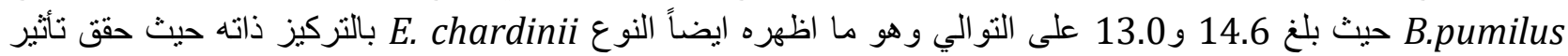

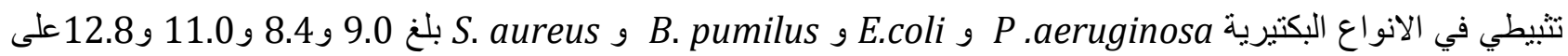
التو الي اما النوع الفطري C. albicans حيث لم يسجل اي ثبيط يذكر.

يوضح جدول 2 وصورة 1 التأثير التثيطي للنوع A.conferta في بعض الميكروبات المدروسة حيث يوضح نأثير

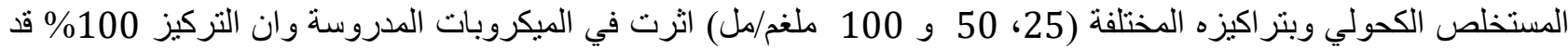

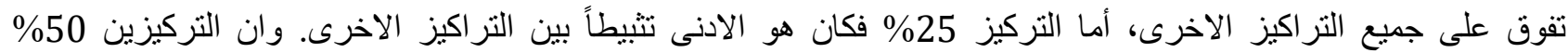
و100\% للنوع النباتي المدروس قد تفوق على المضاد الحيوي (التيتر اسيكلين) بنسبة (13.8 ، 14.6) على التئ التين التي في حين كانت

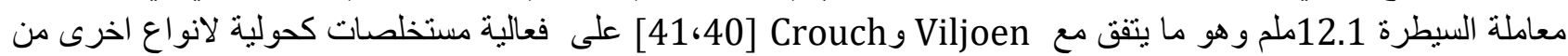

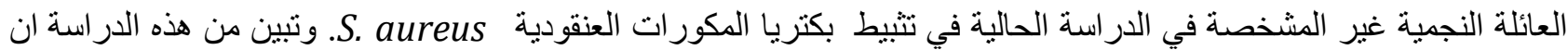

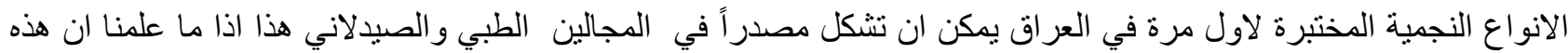

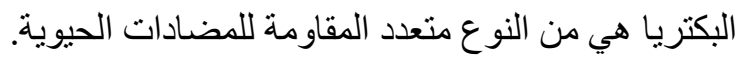

اما النوع E. chardinii فقد حقق تأثير تنبيطي بتركيز 100\% في جميع المايكروبات المدروسة في حين لم بحقق في في

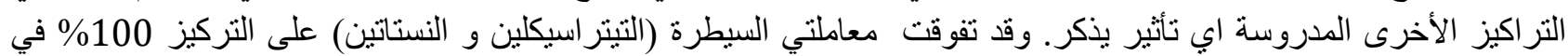

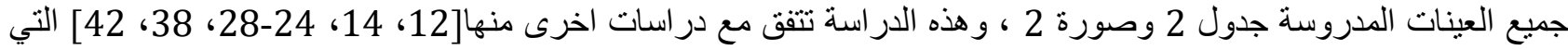

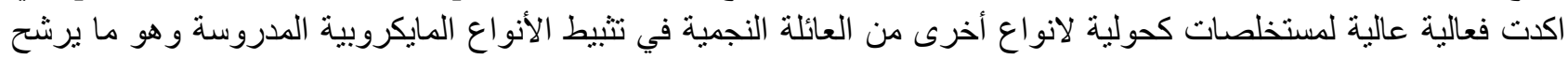

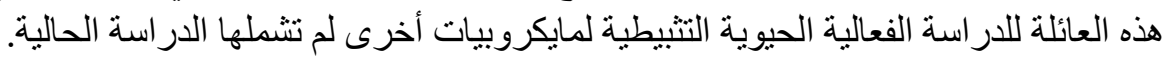

جدول 2: تأثثر المستخلص الكحولي للنو عين Achillea conferta و في بعض الانواع المايكروبية

\begin{tabular}{|c|c|c|c|c|}
\hline \multicolumn{5}{|c|}{ Achillea conferta } \\
\hline ST & $\% 100$ & $\% 50$ & $\% 25$ & انواع الميكروبات \\
\hline 12.1 & 14.6 & 13.8 & 12.1 & staphylococcus \\
\hline 11.3 & 11.1 & 9.8 & 7.9 & E.coli \\
\hline 16.4 & 13.0 & 10.9 & 10.2 & B.pumilus \\
\hline 10.8 & 9.4 & 8.1 & 7.0 & Psudomonas \\
\hline 10.9 & 9.4 & 8.1 & 9.9 & Candida \\
\hline \multicolumn{5}{|c|}{ Echinops chardinii } \\
\hline ST & $\% 100$ & $\% 50$ & $\% 25$ & انواع الميكروبات \\
\hline 14.3 & 9.0 & 0.0 & 0.0 & P. aeruginosa \\
\hline 14.0 & 8.4 & 0.0 & 0.0 & E.coli \\
\hline 12.3 & 11.0 & 0.0 & 0.0 & B.pumilus \\
\hline 13.2 & 12.8 & 0.0 & 0.0 & St.aureus \\
\hline 15.3 & 0.0 & 0.0 & 0.0 & C. albicans \\
\hline
\end{tabular}



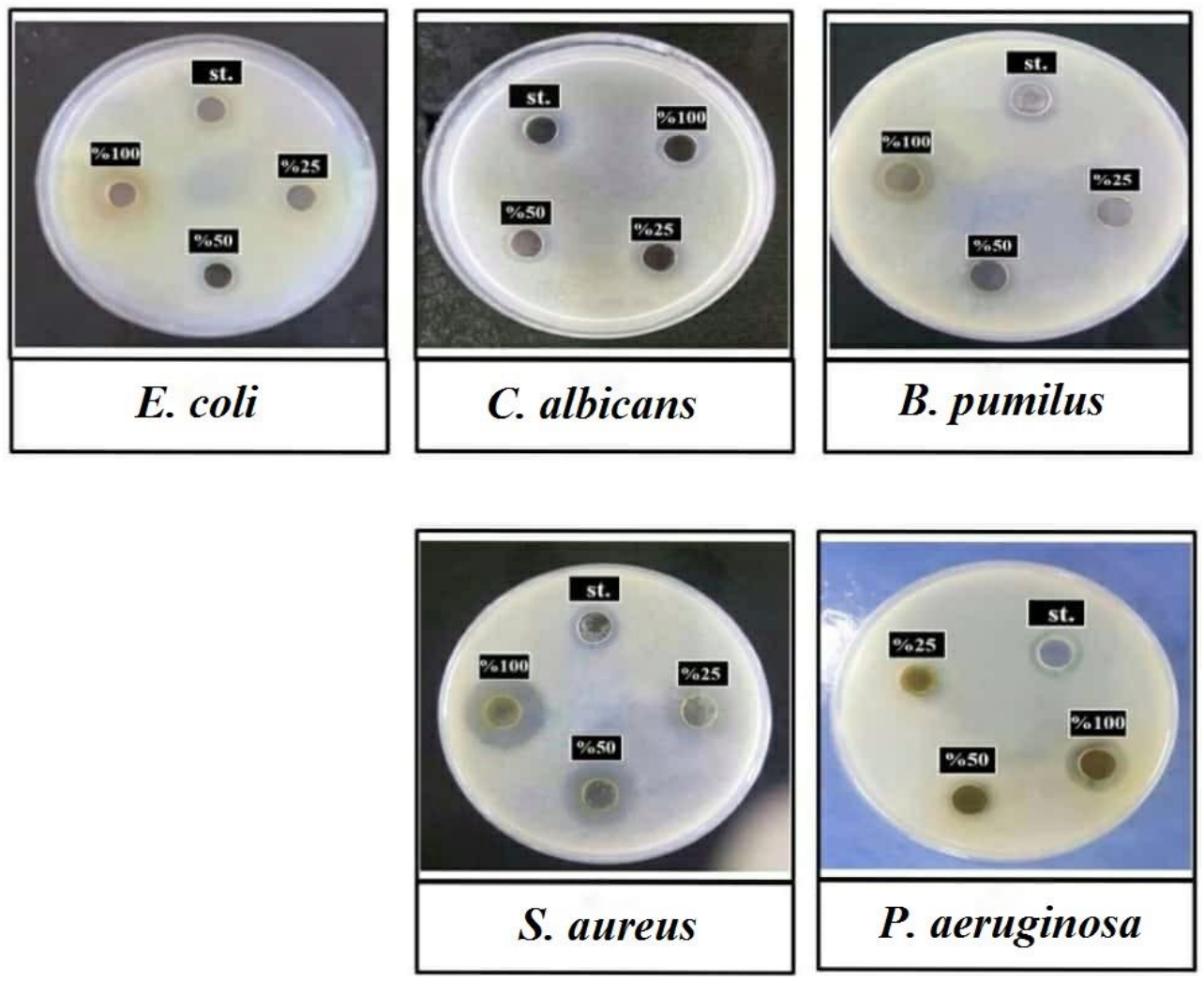

صورة1: التأثير التثبيطي للمستخلص الكحولي للنوع Achillea conferta في بعض الانواع المايكروبية
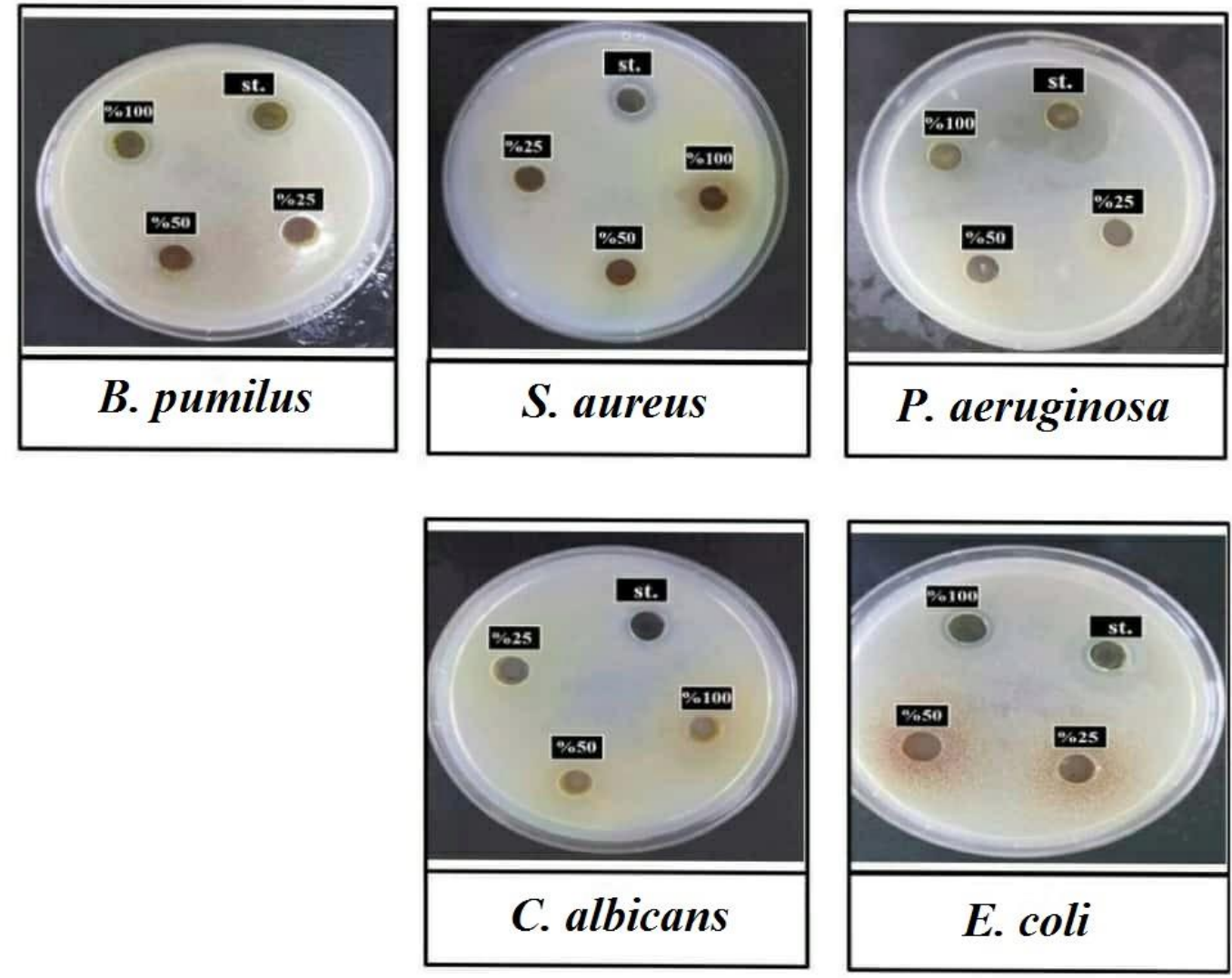

صورة 2: التأثير التثيطي للمستخلص الكحولي للنوع Echinops chardinii في بعض الانواع المايكروبية 


\section{Reference}

1. Kunwar, Rm, Chundamani B , Chowdhary ,C., and Bussmann, R. (2010).Medicinal Plants in Farwest Nepal: Indigenous Uses and Pharmacological Validity. Med. and Arom.Pl.Sc. and Biotech.4: 28-42.

2. Lajter .I. (2015). Biologically active secondary metabolites from Asteraceae and polygonnaceae species .Ph.D.Thesis .University of Szeged, Faculty of Pharmacy.

3. AL-Douri nedhal.A .(2014) some important medicinal plants in Iraq Inter. J. Of Advances In Herbal Alternative Med(IJAHAM) Vol .2(1) $16: 10$-20.

4. Smith, P. M ,(1978) . Chemical evidence in plant taxonomy in Essay in plant taxonomy, Street. H. E (ed.),19 - 38. Academic Press, London and New York.

5. Le .Marchand, L.,(2002). Cancer preventive effect of flavonoids : A review. Biomed. and Pharmacother. $56: 296-301$.

6. Neuhouser, M.L. ,(2004). Dietary flavonoids and cancer risks : Evidence from population studies. Nutr. Cancer $50: 1-7$.

7. Christenhuz.J.M C. and James .W..B., (2016) . The number of known plants species in the world and its annual increase . phytotaxa 2.

8. Mabberley ,D.J.,(2017) .Mabberleys plant -Book Aportable dictionary of plants ,their classification and uses. cambridge university press ,Cambiridge ,UK.1102p.

9. Keely,S.C.and Jansen,R.K. ,(1991). Evidence from chloroplast DNA for the recognition of new tribe. The Tarchonantheae and the Tribal placement of Pluchea (Asteraceae). Systematic botany,16:173-181.

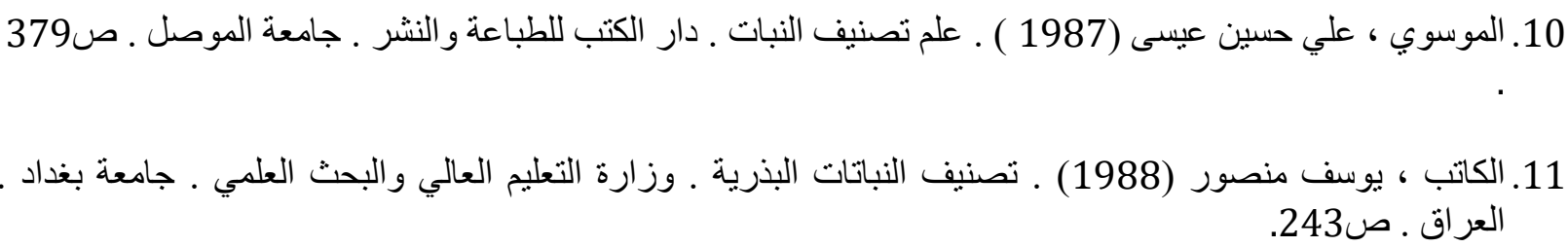

12. Al-Snafi,Ali Esmail. (2015). The Chemical Constituents And Pharmacological "Indian Journal of Pharmaceutical Science and Research." Indian J. of Pharmaceutical Sci. and Res. 5(2): 72-82.

13. Ragasa, C.,Y.; Jeannie W.,and John A.R.(2016). Monoterpene Glycoside and Flavonoids from Blumea Lacera. Journal of Natural Medicines. 61(4): 474-75.

14. AL-Jubory I.,Mouhi T. and Baderen ,S.K ,2017) Agriculture active compound investigation of cola herb (Artemisia abrotanum L.) .Vol .2(1)23.

15. Al-Saadi, Sahar AA Malik .(2017). Variations in Fatty Acid Methyl Ester Contents and Composition in Oil Seeds Gundelia Tournefortii L. (Asteraceae). Advances in Plants \& Agriculture Research. ,6 (6): 00236-00241.

16 محح, زهر اء بكر (2011) ـ دراسة تشريحية و تصنيفية لبعض الانواع البرية ثلاثية الكاربون من العائلة المركبة

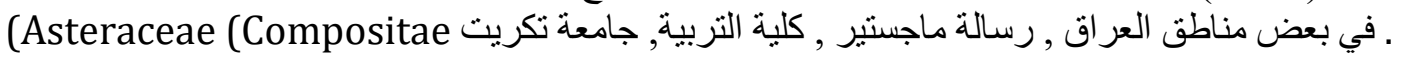


17. العباسي ، شيماء حسن علي (2019). دراسة المحتوى الفعال و الفعالية الحيوية لبعض المراتب البرية من العائلة

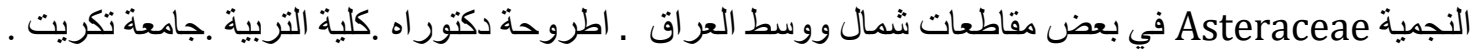

18. Hegnaure , R.(1977). The Chemistry of Composite . In : Heywood, V. H., J. B. Harborne, B. L and Turner. (eds.), The Biology and Chemistry of Composite, Vol. 1.p: 359 - 381. Academic Press, London, New York.

19. Miean, K. H. and S. Mohamed .,(2001). Flavonoid (Myricetin, Quercetin, Kaempferol, Luteolin and Apigenin) Content of Edible Tropical Plants. J. Agric. Food Chem. Vol. 49 (6): $3106-3112$.

20. Namdeo , A.G. , K.R. Mahadik, and S.S. Kadam . (2006). Anti - malarial drug : Artemisia annua .: $710-719$.

21. Jimenez-Medina, E. Garcia- Lora, A. Algarra, I. and Garrido, F,(2006) . Anew extract of the plant Calendula officinalis produces a dual in vitro effect: cytotoxic anti tumer activity and lymphocyte activation. BMC. Cancer 6. p: 119.

22. Emerenciano, V. P., Barbaso K. O., Scotti M. T. and Ferreira M. J.(2007). Selforganizing Maps in Chemotaxonomic Studies of Asteraceae: A Classification of Tribes Using Flavonoids Data. J. Braz. Soc., 18(5): 891 - 899.

23. Evans, W. C. (2009). Trease and evans' pharmacognosy E-book. Elsevier Health Sciences. Artichoke leaf 16th ,. P.184.

24. Trigo, J.R.; Inara R.L.; Nelson I.M. and Thomas M.L. (2003). Chemotaxonomic Value of Pyrrolizidine Alkaloids in Southern Brazil Senecio (Senecioneae: Asteraceae). Biochemical Systematics and Ecology ,31(9): 1011-22.

25. Burkill, H. M. (1985). The Useful Plants of West Tropical Africa, Kew Publishing: UK., p: $1-960$.

26. Adjanahoun, E., Ahyi , Ake-Assi M.R.A.; Elewude , L.;Dramane J.A. and Fadoju K. (1991). Contribution to Ethnobotanical Floristic Studies in Western Nig. Pub.Organization of African Unity,Lagos,Nigeria: $420 \mathrm{pp}$.

27. Kasim,S.; Kafayat O.; Fagbohun, S.F.; Ibitoye, O.E. and Adejumo .(2014). Chemical composition and antibacterial activity of essential oils from asteraceae. Adv. in Biol. Chemist. 4(4): 246-52.

28. Mohamed, Reham A, and Maysa M El Mallah. ,(2015). "Hepatoprotective Effect of Calendula Officinalis Linn (Asteraceae) Flowers Against CCL - Induced Hepatotoxicity in Rats 4." World Appl. Sci. J. 33(12): 1949-59.

29. Funk, V. A. ,(2005). 150 years of thistles, daisies, and sunflowers. The plant Press. Rew. Vol. 8: 1 - 12 .

30. Rechinger, K. H. and Paul A. (1964). Flora of Lowland Iraq. Weinheim J. Cramer. pp. 389-398.

31. Shihata, I. M. , (1951) ."A pharmacological study of Anagallis arvensis". M.D. Thesis Cairo University. 
32. Peach, K.; Tracey, M.V., (1965) . "Modern methods of plant analysis". Vol.3, Springer Verlag, Berlin.

33. Roopashree, T. S., Dang, R., Rani, S. R. H., \& Narendra, C. (2008). Antibacterial activity of antipsoriatic herbs: Cassia tora, Momordica charantia and Calendula officinalis. International Journal of Applied research in Natural products, 1(3), 20-28.

34. Rios, J. L., Recio, M. C., \& Villar, A. (1987). Antimicrobial activity of selected plants employed in the Spanish Mediterranean area. Journal of ethnopharmacology, 21(2), 139-152.

35. Mitscher, L.A. ;Leu, R. ;Bathala, M.S. ; Beal, J.L. and White, R.(1972). Antimicrobial agents from higher plants . I. Introduction, rationale, and methodology. Pub Med $.35(2): 157-166$.

36. Atlas , R.M. (1995) . Pathogenesis of infectious Disease In : Principle of Microbiology .1st ed ., Mosby-Yearbook, Inc .St.Loui .Baltimore .

37. Baron, E. J., Peterson, L.R and Finegold, S.M. (1994). Bailey and Scotts Diagnostic Microbiology. 9th. ed., Mosby Baltimor, London.

38. Saeidnia, S. ; N. Yasa ; A.R. Johari and A. Shafiei. (2005). Isolation and identification of flavonoid constituents from Achillea conferta DC. J. of Medicinal Plants 4 (14).

39. Crouch, N. R. A. ;Langlois, D. A. ;Mulholland and Nair J. J.(2005). "A Novel Alkylamide from the Leaves of Acmella Caulirhiza (Asteraceae), a Traditional Surface Analgesic. South African J. of Botany 71: 228-30.

40. Viljoen, A, Van Vuuren, S.; Ernst ,E.; Klepser, M. ; Demirici, B. ; Baser H, and Wyk,.E . (2003). Osmitopsis Asteriscoides (Asteraceae)-the Antimicrobial Activity and Essential Oil Composition of a Cape-Dutch Remedy. J. of Ethnopharmacology 88(23): $137-43$.

41. Dulgar, B. and A. Gonus, (2004). Antimicrobial Activity of Some Turkish Medicinal Plants. Pakistan. J.of Biological Sciences 7 (9): 1559-1562.

42. Macêdo, Maria EM ; Rotraut .A.C.; Telma .SM .G.; Antonio. MG.; Anjos, B. O.; Nelymer .M.M. and Carlos L zani .( 1997). "Screening of Asteraceae (Compositae) Plant Extracts for Larvicidal Activity against Aedes Fluviatilis (Diptera: Culicidae). Memórias do Instituto Oswaldo Cruz, 92(4): 565-70. .

43. Siddiqui, A. A. and Ali, M.,(1997). Practical Pharmaceutical chemistry" . 1st ed., CBS Publishers and Distributors, New Delhi: pp.126-131.

44. Gibbs, R. D., (1974 )."Chemotaxonomy of Flowering Plants" . McGill Queen's University Press-Montreal and London1974;1.

45. Harborn, J.B.(1994)."The Flavonoids". Advanced in Research since 1986.london,VK:Chapmonand Hall. 


\title{
The inhibitory effect for Acillia conferta and Echinops charadinii from Asteraceae family in some microbe species
}

\author{
Shaima Hassan Ali AL-Abbasi
}

Department of Biology, College of Education, University of samarra, Iraq (shaimaa.h.ali1986@gmail.com)

\begin{tabular}{|c|c|}
\hline Article Information & Abstract \\
\hline $\begin{array}{l}\text { Received: } 10 / 07 / 2020 \\
\text { Accepted: } 25 / 08 / 2020\end{array}$ & $\begin{array}{l}\text { The present study was designed to explore the biochemical properties } \\
\text { and microbial activity of two natural plant species (Achillea conferta } \\
\text { Echinops charadinii). Biochemical analysis revealed the presence of } \\
\text { different types of secondary metabolites such as (turbines phenols and }\end{array}$ \\
\hline Keywords: & \\
\hline $\begin{array}{l}\text { Achillea conferta, } \\
\text { Echinops chardini, } \\
\text { Asteraceae, } \\
\text { Staphylococcus aureus, } \\
\text { Terpenes, Phenols, } \\
\text { Flavonoids, Pseudomonas } \\
\text { aeruginosa, Candida } \\
\text { albicans }\end{array}$ & $\begin{array}{l}\text { methanol extracts of the two plant species were evaluatedfor } \\
\text { antibacterial activity against five medically important pathogens: } \\
\text { Staphylococcus aureus ' Bacillus pumilus Escherichia coli } \text { Pseudomonas } \\
\text { aeruginosa a and one fungus Candida Albicans. The results showed } \\
\text { different activities against all the tested pathogens in the different } \\
\text { concentrations. Staphylococcus aureus was the most susceptible } \\
\text { pathogen to A. conferta } 100 \mathrm{mg} / \mathrm{ml} \text { in comparison to Tetracycline. (14.6 } \\
-12.1 \text { Respectively). The concentration } 100 \mathrm{mg} / \mathrm{ml} \text { was higher than all } \\
\text { the other concentration in both species of plant in A.conferta scored }(9.4- \\
\text { 14.6) mm diameter of inhibition ,in E.charadinii scored ( } 8.4-12.8) \mathrm{mm} \\
\text { in all bacterial species except for the fungal species C.albicans wich did } \\
\text { not record any inhibition, In conclusion 'A. conferta methanol extract } \\
\text { could treat diverse human bacterial pathogens due to its high } \\
\text { antimicrobial activity. }\end{array}$ \\
\hline
\end{tabular}

